\title{
Revisiting Black's Experiments on the Latent Heats of Water
}

\begin{abstract}
J. Güémez, Departamento de Física Aplicada, Universidad de Cantabria, E-39005 Santander, Spain; guemezj@unican.es

C. Fiolhais and M. Fiolhais, Departamento de Física and Centro de Física Computacional, Universidade de Coimbra, P-3004-516 Coimbra, Portugal; tcarlos@teor.fis.uc.pt; tmanuel@teor.fis.uc.pt
\end{abstract}

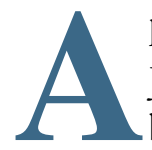
lthough born in Bordeaux, France, Joseph Black was purely Scottish by blood. He began studying medicine at the University of Glasgow, where he first became interested in chemistry. After completing his medical studies in Edinburgh, Black returned to Glasgow in 1756 to become a professor of medicine. His main interest, however, remained chemistry and physics, and his lecture courses eventually grew to attract students from all over Europe and even America. Featured in his lectures were vivid descriptions of his own discoveries and experiments, and in 1766, when he accepted a chair at the University of Edinburgh, he was followed by many of his students.

As a professor at Glasgow, Black became interested in calorimetry and performed experiments on the specific heat and latent heats of water. He was the first to distinguish between temperature and heat. ${ }^{1}$ The notion of specific heat has been attributed to him, ${ }^{2}$ and the experiments to determine the specific heat (using the mixture $\operatorname{method}^{3}$ ), which are common in introductory physics laboratories, go back to Black. On the other hand, Black pointed out that previous ideas on melting and freezing, e.g., that the fusion of ice is instantaneous and requires almost no heat, ${ }^{2}$ were wrong. He introduced the term latent heat to describe the energy that seems to "hide" when melting occurs, reappearing in freezing, and also to hide in evaporation, reappearing in condensation. ${ }^{4}$

Black's calorimetric experiments come to us in reports written by his students. One such report refers to the determination of the latent heat of melting ice:

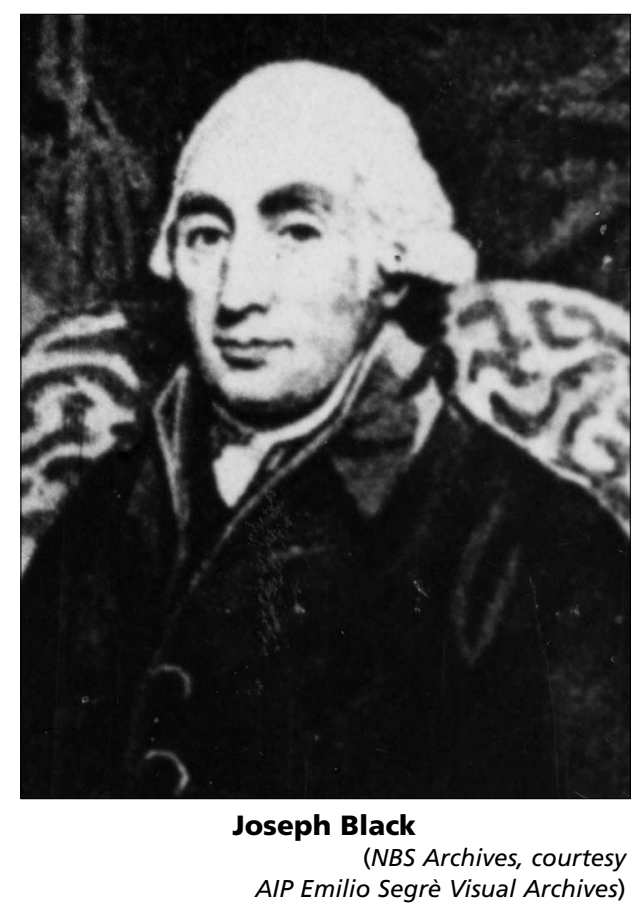

\begin{abstract}
"In order to understand this absorption of heat into the melting ice and concealment of it in the water more distinctly, I made (among others) the following experiment. I put a lump of ice into an equal quantity of water heated to the temperature $\left[80^{\circ} \mathrm{C}\right]$ and the result was that when the ice was all melted the fluid was no hotter than water just ready to freeze." 5
\end{abstract}

A second experiment refers to the latent heat of vaporization of water:

"I procured some cylindrical tin-plate vessels, about 4 or 5 inches diameter and flat bottomed. Putting a small quantity 


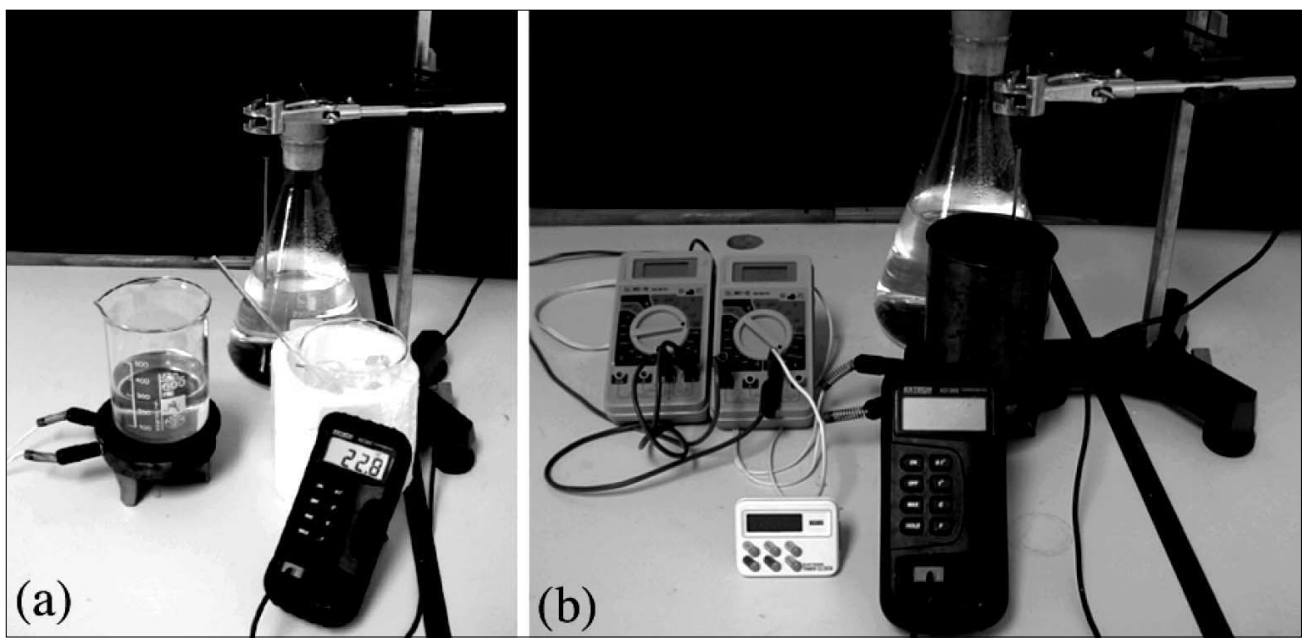

Fig. 1. Modern setups for the two experiments described by Black. (a) Setup for determining the water latent heat of fusion; (b) setup for determining the water latent heat of evaporation.

of water into them, of the temperature $\left[10^{\circ} \mathrm{C}\right]$, I set them upon a red-hot stove taking care that the fire should be pretty regular. After four minutes the water began sensibly to boil and in twenty minutes more it was all boiled off." 6

The reproduction of historical experiments of thermodynamics, leading to the same results obtained by the pioneers of the subject, may help students to gain deeper insights on that subject. On the other hand, in doing some old experiments, one often comes to the conclusion that they are not completely appropriate to accomplish their purposes. This is especially true in thermodynamics where heat losses are always present.

One may wonder whether Black's experiments do in fact give accurate results. In order to answer this question and since we think that modern analysis of historical experiments has pedagogical interest, we carried out these experiments with the equipment shown in Fig. 1, which can be found in any introductory physics laboratory. Black's experiment to find the latent heat of ice leads to an accurate value (other experiments to determine the latent heat of fusion of ice have been recently reported in the literature $\left.^{7}\right)$. However, Black's experiment to determine the latent heat of steam, if naively interpreted, gives a result that differs from the accept- ed value by $25 \%$. In order to get more accurate values, cooling by radiation has to be considered.

\section{Latent Heat of Fusion}

A mass $m_{\mathrm{w}}$ of water, at initial temperature $t_{\mathrm{i}}$, is mixed with a mass $m_{\mathrm{i}}^{\mathrm{I}}$ of ice at $0^{\circ} \mathrm{C}$ in a calorimeter [a glass vessel with a Styrofoam wrapping, see Fig. 1(a)]. The temperature of the water is first raised to a few degrees above the desired initial temperature, $t_{\mathrm{i}}$. The system then starts to cool down and, when the temperature $t$. is reached, the water is rapidly poured onto the ice inside the calorimeter (kept, as the ice, at $\left.0^{\circ} \mathrm{C}\right)$. The ice-water mixture is vigorously stirred with a glass stirring rod until its temperature stabilizes at a value $t_{\mathrm{f}}$ It is important to keep mixing during the approximately three minutes (the frictional work is negligible) required. Finally, the remaining ice $m_{\mathrm{f}}$ if any, is removed and weighted. Then, $m_{\mathrm{I}}=m_{\mathrm{i}}^{\mathrm{I}}-m_{\mathrm{f}}^{\mathrm{I}}$ is the mass of the melted ice.

Table I shows Black's measurements, as well as the data obtained in our own experiment for different quantities of water and ice.

For a pure substance that undergoes both a temperature change and a phase transition due to contact with a heat source, the heat absorbed is $Q=m \lambda+m c \Delta t$, with $m$ its mass, $\lambda$ the latent heat of the phase transition, $c$ the specific heat 
Table I. Data for mixtures of ice at $0^{\circ} \mathrm{C}$ and hot water. $m_{w}$ stands for the mass of liquid water. The initial mass of ice is $m_{i}{ }^{\prime}$ and the final mass of ice (not melted) is $m_{f}^{\prime}$. The water initial temperature and the final mixture temperature are $t_{i}$ and $t_{f}$, respectively.

\begin{tabular}{|l|r|r|l|l|l|}
\hline Run & $m_{\mathrm{W}}(\mathrm{g})$ & \multicolumn{1}{|c|}{$m_{\mathrm{i}}(\mathrm{g})$} & \multicolumn{1}{|c|}{$m_{\mathrm{f}}(\mathrm{g})$} & $t_{\mathrm{i}}\left({ }^{\circ} \mathrm{C}\right)$ & $t_{\mathrm{f}}\left({ }^{\circ} \mathrm{C}\right)$ \\
\hline Black & & & 0. & 80.0 & 0.0 \\
1 & $186.7 \pm 0.2$ & $188.1 \pm 0.2$ & $0.5 \pm 0.2$ & $80.0 \pm 0.1$ & $0.0 \pm 0.1$ \\
2 & $179.8 \pm 0.2$ & $178.2 \pm 0.2$ & $0.4 \pm 0.2$ & $80.0 \pm 0.1$ & $0.0 \pm 0.1$ \\
3 & $172.0 \pm 0.2$ & $218.6 \pm 0.2$ & $44.4 \pm 0.2$ & $80.0 \pm 0.1$ & $-0.2 \pm 0.1$ \\
4 & $172.1 \pm 0.2$ & $263.3 \pm 0.2$ & $89.3 \pm 0.2$ & $80.0 \pm 0.1$ & $-0.2 \pm 0.1$ \\
5 & $173.9 \pm 0.2$ & $148.5 \pm 0.2$ & $0.0 \pm 0.2$ & $80.0 \pm 0.1$ & $5.4 \pm 0.1$ \\
6 & $170.6 \pm 0.2$ & $128.1 \pm 0.2$ & $0.0 \pm 0.2$ & $80.0 \pm 0.1$ & $9.6 \pm 0.1$ \\
\hline
\end{tabular}

(at constant pressure), assumed to be constant, and $\Delta t=t_{\mathrm{f}}-t_{\mathrm{i}}$ the temperature variation. For the liquid water, $Q_{\mathrm{W}}=m_{\mathrm{W}} c_{\mathrm{W}}\left(t_{\mathrm{f}}-t_{\mathrm{i}}\right)$ (the specific heat of water, $c_{\mathrm{W}}$, is considered to be constant between $0^{\circ} \mathrm{C}$ and $80^{\circ} \mathrm{C}$ ) and, for the melted ice, $Q_{\mathrm{I}}=m_{\mathrm{I}} \lambda_{\mathrm{f}}+m_{\mathrm{I}} c_{\mathrm{W}}\left(t_{\mathrm{f}}-0\right)$, where $\lambda_{\mathrm{f}}$ is the latent heat of fusion of ice. When the final temperature is $t_{\mathrm{f}}=0^{\circ} \mathrm{C}$, the calorimeter does not gain or lose heat and $Q_{\mathrm{I}}=-Q_{\mathrm{W}}$. Thus,

$$
\lambda_{\mathrm{f}}=c_{\mathrm{W}} t_{\mathrm{i}} \frac{m_{\mathrm{W}}}{m_{\mathrm{I}}} .
$$

In the original experiment by Black, $m_{\mathrm{w}}=m_{\mathrm{I}}$, $t_{\mathrm{i}}=80^{\circ} \mathrm{C}$ (and $t_{\mathrm{f}} \approx 0^{\circ} \mathrm{C}$ ), leading to $\lambda_{\mathrm{f}}=80 c_{\mathrm{W}}$. Using $c_{\mathrm{W}}=4.18 \mathrm{Jg}^{-1} \mathrm{C}^{-1}$ (a value later found by Joule), one finds $\lambda_{\mathrm{f}}=334 \mathrm{Jg}^{-1}$, which is close to the current value $333.9 \mathrm{Jg}^{-1}$. ${ }^{8}$

However, when the final temperature of water differs from $0^{\circ} \mathrm{C}$, heating of the calorimeter has to be taken into account in the heat balance and Eq. (1) does not apply. A calorimeter is an adiabatic system (there is no heat exchange with its surroundings). For water mixed with ice in the calorimeter, we have

$$
\begin{aligned}
& Q_{\mathrm{I}}+Q_{\mathrm{W}}+Q_{\mathrm{C}} \\
& m_{\mathrm{I}} \lambda_{\mathrm{f}}+m_{\mathrm{I}} c_{\mathrm{W}}\left(t_{\mathrm{f}}-0\right)+m_{\mathrm{W}} c_{\mathrm{W}}\left(t_{\mathrm{f}}-t_{\mathrm{i}}\right)+m_{\mathrm{c}} c_{\mathrm{W}}\left(t_{\mathrm{f}}-0\right) \\
&=0 .
\end{aligned}
$$

The calorimeter has been modeled by an (equivalent) amount of water, $m_{\mathrm{C}}$, which absorbs the same heat, $Q_{C}$, as the calorimeter when the mixture takes place. ${ }^{3}$ From Eq. (2), we have

$$
\lambda_{\mathrm{f}}=c_{\mathrm{W}}\left(t_{\mathrm{i}} \frac{m_{\mathrm{W}}}{m_{\mathrm{I}}}-t_{\mathrm{f}} \frac{m_{\mathrm{W}}+m_{\mathrm{I}}+m_{\mathrm{C}}}{m_{\mathrm{I}}}\right) .
$$

The equivalent in water of the calorimeter depends on the thermodynamical process, but we performed a single experiment to estimate $m_{C}$ (note that all runs in Table I were done in similar conditions). We mixed equal masses of hot and cold water (approximately $170 \mathrm{~g}$ each, as in Table I), at $92.7^{\circ} \mathrm{C}$ and $2.7^{\circ} \mathrm{C}$, respectively (as in the experiments of Table I). After stirring during three minutes, the temperature $41.9^{\circ} \mathrm{C}$ was reached. From an equation like Eq. (2), but applied to hot water, cold water, and the calorimeter, we found $m_{C} \approx 57 \pm 4 \mathrm{~g}$.

Using the $m_{C}$ in Eq. (3) we obtain values for $\lambda_{f}$, which are given in the third column of Table IV. These values are all pretty close to the current value.

\section{Latent Heat of Vaporization}

We placed water in a copper vessel with a flat bottom [see Fig. 1(b)]. The temperature was raised to the boiling point, $\approx 100^{\circ} \mathrm{C}$ at a pressure of $1.010 \mathrm{bar}$ (atmospheric pressure), and then the water was totally converted to steam. An electric hotplate served as the heat source. Let $\mathrm{P}$ be the constant power supplied during the process, $\tau_{1}$ be the time for water to reach the boiling point starting from the temperature $t$. (room temperature), and $\tau_{2}$ be the time for the water to evaporate completely.

One should consider that the container is always radiating to the environment since its temperature is higher than that of the air. Thus, in the heating and evaporation processes,

$$
\begin{aligned}
& P \tau_{1}=m_{\mathrm{W}} c_{\mathrm{W}}\left(100-t_{\mathrm{i}}\right)+Q^{\text {heating }}, \\
& P \tau_{2}=m_{\mathrm{W}} \lambda_{\mathrm{v}}+Q^{\text {boiling }}
\end{aligned}
$$


where $m_{\mathrm{W}}$ is the mass of water, $\lambda_{\mathrm{v}}$ the latent heat of vaporization, and $Q^{\text {heating }}$ and $Q^{\text {boiling }}$ are energy exchanges with the environment (heat losses) in the heating and boiling processes, respectively.

Following Ref. 9, not taking into account heat losses (i.e., $Q^{\text {heating }}=Q^{\text {boiling }}=0$ ), with $t_{\mathrm{i}}=$ $10^{\circ} \mathrm{C}, \tau_{1}=4 \mathrm{~min}$, and $\tau_{2}=20 \mathrm{~min}$, as in Black's work,

$$
\lambda_{\mathrm{v}}=\frac{\tau_{2}}{\tau_{1}} c_{\mathrm{W}}\left(100-t_{\mathrm{i}}\right),
$$

one obtains $\lambda_{\mathrm{v}}=450 c_{\mathrm{W}}=1881.0 \mathrm{Jg}^{-1}$, very different from the current value, $2261.1 \mathrm{Jg}^{-1}$.

In Table II we show Black's measurements and our own data collected in six runs of the same experiment, using different quantities of water. The fourth column of Table IV shows our own results for the latent heat of evaporation using Eq. (5). Since the values are too high, we have to take into account heat losses.

The effect of radiation can be dealt with using Newton's law of cooling. ${ }^{10}$ To estimate the energy loss of the water in the cooling process, we carried out the following experiment. We heated a mass of water in the copper vessel up to the boiling point. Then we let it cool down to room temperature, $t_{\mathrm{R}}$, in order to measure the cooling rate of water. We performed this cooling experiment twice with $m_{\mathrm{W}}=100 \mathrm{~g}$ and $m_{\mathrm{W}}=$ $300 \mathrm{~g}$. In Table III we report the elapsed times, $\tau$, and temperatures, $t$.

The power lost to the environment is

$$
\frac{\delta Q}{d \tau}=m_{\mathrm{W}} c_{\mathrm{W}} \frac{d t}{d \tau} .
$$

Using Newton's law of cooling ${ }^{10}$ in its differential form,

$$
\frac{d t}{d \tau}=-k_{\mathrm{m}}\left(t-t_{\mathrm{R}}\right)
$$

where $k_{\mathrm{m}}$ is the cooling parameter (the index $m$ stresses that $k$ depends on the mass of water). Eq. (6) becomes
Table II. Data obtained in water vaporization experiments. $\boldsymbol{m}_{\mathrm{w}}$ is the mass of water, $t_{i}$ its initial temperature, $\tau_{1}$ the elapsed time for water to start boiling, and $\tau_{2}$ the elapsed time for water to evaporate completely.

\begin{tabular}{|l|c|l|l|l|}
\hline Run & $m_{\mathrm{w}}(\mathrm{g})$ & $t_{\mathrm{i}}\left({ }^{\circ} \mathrm{C}\right)$ & $\tau_{1}(\mathrm{~s})$ & $\tau_{1}+\tau_{2}(\mathrm{~s})$ \\
\hline Black & & 10. & 240 & 1440 \\
1 & $100.3 \pm 0.2$ & $19.5 \pm 0.1$ & $115 \pm 5$ & $1066 \pm 8$ \\
2 & $100.4 \pm 0.2$ & $19.9 \pm 0.1$ & $118 \pm 5$ & $1069 \pm 8$ \\
3 & $150.4 \pm 0.2$ & $20.4 \pm 0.1$ & $164 \pm 5$ & $1506 \pm 8$ \\
4 & $200.3 \pm 0.2$ & $20.5 \pm 0.1$ & $195 \pm 5$ & $1977 \pm 8$ \\
5 & $250.2 \pm 0.2$ & $20.4 \pm 0.1$ & $271 \pm 5$ & $2625 \pm 8$ \\
6 & $300.2 \pm 0.2$ & $20.7 \pm 0.2$ & $320 \pm 5$ & $3085 \pm 8$ \\
\hline
\end{tabular}

$$
\frac{\delta Q}{d \tau}=-k_{\mathrm{m}} m_{\mathrm{W}} c_{\mathrm{W}}\left(t-t_{\mathrm{R}}\right) .
$$

In the heating process, we observed that the temperature varies linearly with time,

$t=t_{\mathrm{R}}+\frac{100-t_{\mathrm{R}}}{\tau_{1}} \tau$. The power lost in the heating process is then

$$
\frac{\delta Q^{\text {heating }}}{d \tau}=-k_{\mathrm{m}} m_{\mathrm{W}} c_{\mathrm{W}} \frac{100-t_{\mathrm{R}}}{\tau_{1}} \tau .
$$

During boiling, the temperature of the recip-

Table III. Times and temperatures for (a) cooling $100 \mathrm{~g}$ of water in an environment at $t_{\mathrm{R}}=$ $19.7^{\circ} \mathrm{C}$ and (b) cooling $300 \mathrm{~g}$ of water at $t_{\mathrm{R}}=$ $21.0^{\circ} \mathrm{C}$. In both cases, cooling occurred in a copper vessel with $155 \mathrm{~g}$.

\begin{tabular}{|l|c|c|c|}
\hline \multicolumn{2}{|c|}{ (a) } & \multicolumn{2}{c|}{ (b) } \\
\hline$\tau(\mathrm{s})$ & $t\left({ }^{\circ} \mathrm{C}\right)$ & $\tau(\mathrm{s})$ & $t\left({ }^{\circ} \mathrm{C}\right)$ \\
\hline 0 & $100.2 \pm 0.1$ & 0 & $100.1 \pm 0.1$ \\
10 & $98.8 \pm 0.1$ & 10 & $99.6 \pm 0.1$ \\
20 & $96.1 \pm 0.1$ & 20 & $98.7 \pm 0.1$ \\
30 & $93.7 \pm 0.1$ & 30 & $97.5 \pm 0.1$ \\
40 & $90.5 \pm 0.1$ & 40 & $96.5 \pm 0.1$ \\
50 & $88.6 \pm 0.1$ & 50 & $95.4 \pm 0.1$ \\
60 & $86.4 \pm 0.1$ & 60 & $94.4 \pm 0.1$ \\
\hline
\end{tabular}


Table IV. Latent heat of fusion of ice, whose standard value is $\lambda_{f}$ $=333.9 \mathrm{Jg}^{-1}$, and latent heat of water evaporation, whose standard value is $\lambda_{v}=2261.1 \mathrm{Jg}^{-1} .{ }^{8}$ We note that Eq. (1) only applies when $t_{f}=0^{\circ} \mathrm{C}$, which is not the case for runs 5 and 6 of the fusion experiment.

\begin{tabular}{|l|l|l|l|l|}
\hline Run & $\begin{array}{c}\lambda_{f}\left(\mathrm{Jg}^{-1}\right) \\
{[\mathrm{Eq} .(1)]}\end{array}$ & $\begin{array}{c}\lambda_{\mathrm{f}}\left(\mathrm{Jg}^{-1}\right) \\
{[\mathrm{Eq} .(3)]}\end{array}$ & $\begin{array}{c}\lambda_{\mathrm{v}}\left(\mathrm{Jg}^{-1}\right) \\
{[\mathrm{Eq} .(5)]}\end{array}$ & $\begin{array}{c}\lambda_{\mathrm{v}}\left(\mathrm{Jg}^{-1}\right) \\
{[\mathrm{Eq} .(15)]}\end{array}$ \\
\hline Black & 334 & & 1881 & \\
1 & 333 & $333 \pm 6$ & 2710 & $2540 \pm 180$ \\
2 & 338 & $338 \pm 6$ & 2700 & $2440 \pm 170$ \\
3 & 332 & $332 \pm 6$ & 2700 & $2350 \pm 130$ \\
4 & 331 & $332 \pm 6$ & 3000 & $2650 \pm 150$ \\
5 & $(343)$ & $334 \pm 6$ & 2890 & $2410 \pm 180$ \\
6 & $(351)$ & $334 \pm 6$ & 2860 & $2370 \pm 190$ \\
\hline
\end{tabular}

ient remains at $t=100^{\circ} \mathrm{C}$. Hence, the power lost during boiling is

$$
\frac{\delta Q^{\text {heating }}}{d \tau}=-k_{\mathrm{m}} m_{\mathrm{W}} c_{\mathrm{W}}\left(100-t_{\mathrm{R}}\right) .
$$

Integrating, we find

$$
\begin{aligned}
& Q^{\text {heating }}=-k_{\mathrm{m}} m_{\mathrm{W}} c_{\mathrm{W}}\left(100-t_{\mathrm{R}}\right) \frac{\tau_{1}}{2}, \\
& Q^{\text {boiling }}=-k_{\mathrm{m}} m_{\mathrm{W}} c_{\mathrm{W}}\left(100-t_{\mathrm{R}}\right) \tau_{2} .
\end{aligned}
$$

Using the data from Table III in the integral form of Newton's law of cooling [integral of Eq. (7)],

$$
k_{\mathrm{m}}=-\frac{1}{\tau} \ln \frac{t(\tau)-t_{\mathrm{R}}}{t(0)-t_{\mathrm{R}}},
$$

one obtains the (mass dependent) cooling parameter: $k_{100}=3.59 \times 10^{-3} \mathrm{~s}^{-1}$ and $k_{300}=1.36$ $\times 10^{-3} \mathrm{~s}^{-1}$ for $m_{\mathrm{W}}=100 \mathrm{~g}$ and $m_{\mathrm{W}}=300 \mathrm{~g}$, respectively. For the (mass independent) quantity $m_{\mathrm{W}} c_{\mathrm{W}} k_{\mathrm{m}}$, one obtains $100 c_{\mathrm{W}} k_{100}=1.72$ $\mathrm{W}^{\circ} \mathrm{C}^{-1}$ and $300 c_{\mathrm{W}} k_{300}=1.79 \mathrm{~W}^{\circ} \mathrm{C}^{-1}$. Inserting the average value, $1.75 \mathrm{~W}^{\circ} \mathrm{C}^{-1}$, back into Eq. (11) we obtain the following heat losses during heating and boiling:

$$
\begin{aligned}
& \left|Q^{\text {heating }}\right|=1.75\left(100-t_{\mathrm{R}}\right) \frac{\tau_{1}}{2} \approx 71.6 \tau_{1}, \\
& \left|Q^{\text {boiling }}\right|=1.75\left(100-t_{\mathrm{R}}\right) \tau_{2} \approx 143.2 \tau_{2} .
\end{aligned}
$$

Taking into account these heat losses in Eq. (4), the energy balance equations are

$$
\begin{aligned}
& P \tau_{1}=m_{\mathrm{W}} c_{\mathrm{W}}\left(100-t_{\mathrm{i}}\right)+71.6 \tau_{1}, \\
& P \tau_{2}=m_{\mathrm{W}} \lambda_{\mathrm{v}}+143.2 \tau_{2} .
\end{aligned}
$$

Eliminating $P$ in these equations, we obtain

$$
\lambda_{\mathrm{v}}=\frac{\tau_{2}}{\tau_{1}}\left[c_{\mathrm{W}}\left(100-t_{\mathrm{i}}\right)-\frac{71.6}{m_{\mathrm{W}}} \tau_{1}\right] .
$$

Taking $c_{\mathrm{W}}=4.18 \mathrm{Jg}^{-10} \mathrm{C}^{-1}$ and inserting data given in Table II in this equation, one obtains the results displayed in the last column of Table IV. They improved with respect to the results arising from Eq. (5) (the average deviation is less than $10 \%$ now). However, one should notice the large uncertainty estimates. In these experiments to determine the latent heat of vaporization, uncertainties are mainly associated with difficulties in measuring exact times when water starts to boil and when water evaporates completely. The heat absorbed by the metallic vessel and the water losses during heating and steam condensation in the recipient walls are other sources of uncertainty. ${ }^{\text {? }}$

\section{Comments}

In summary, we have carried out Black's experiments on the latent heats of water, which may be done nowadays for teaching thermodynamics. The first one is usually performed in introductory physics laboratories, either at high school or college level, in order to obtain the latent heat of fusion of ice, but we pointed out the need for using the water equivalent of the calorimeter when the final temperature is different from $0^{\circ} \mathrm{C}$. On the other hand, the determination of the latent heat of vaporization using Black's experiment requires a model for heat losses. We used Newton's law of cooling, but nevertheless it turned out to be difficult to obtain the accepted value with a precision much better than $10 \%$. The uncertainties are simply too large to make this method of great practical value. The most common method to determine the latent heat of water evaporation is the so- 
called Berthelot's method. ${ }^{3,11}$

We would like to stress that mastering the scientific method also requires understanding why, sometimes, some experiments do not work well. Failed experiments, suitably presented and discussed, may be of pedagogical value.

\section{References}

1. S.C. Brown, "The caloric theory of heat," Am. J. Phys. 18, 367 (Sept. 1950).

2. L.W. Taylor, Physics: The Pioneer Science. Volume I. Mechanics Heat, Sound (Dover Publications, New York), Ch. 20, p. 267. This reproduces the original Lectures on Elements of Chemistry, given by Black at the University of Edinburgh, published from his manuscripts by John Robinson (Longman \& Rees, London, 1803).

3. H.S. Allen and H. Moore, A Textbook of Practical Physics (MacMillan, London, 1965), p. 296.

4. P.H. Bligh and R. Haywood, "Latent heat - Its meaning and measurement," Eur. J. Phys. 7, 245 (1986).

5. See Ref. 2. Note that Black's thermometers were graduated in Fahrenheit degrees, but temperatures have been converted here to Celsius.

6. See Ref. 2. Italics added to call attention to the fact that both times have to be measured in "regular" heating conditions.

7. S.Y. Mak and C.K.W. Chun, "The measurement of the specific latent heat of fusion of ice: two improved methods," Phys. Educ. 35, 181 (May 2000).

8. H.U. Fuchs, The Dynamics of Heat (Springer, New York, 1996), p. 659.

9. C.D. Galles, "Revival of Black's experiment," Am. J. Phys. 47, 1008 (Nov. 1979).

10. J.W. Dewdney, "Newton's law of cooling as a laboratory introduction to exponential decay functions," Am. J. Phys. 27, 668 (Dec. 1959).

11. H. Lindeman and A. Lavie, "Instrument for the measurement of the heat of vaporization of water," Am. J. Phys. 29, 705 (Oct. 1961). 